\title{
Studies on a Collection of Gram-Negative Bacterial Strains Showing Resemblance to Moraxellae: Examination by Conventional Bacteriological Methods
}

\author{
K. B $\emptyset$ VRE, J. E. FUGLESANG, S. D. HENRIKSEN, S. P. LAPAGE, \\ H. LAUTROP, and J. J. S. SNELL
}

Kaptein W. Wilhelmsen og Frues Bakteriologiske Institutt, University of Oslo, Rikshospitalet, Oslo 1, Norway; National Collection of Type Cultures, Colindale, London NW 9, England; and Staten Seruminstitut, 2300 Copenhagen S, Denmark

\begin{abstract}
A collection of 36 gram-negative bacterial strains, showing some resemblance to moraxellae and possibly belonging to Moraxella or related genera, was examined by a number of conventional tests in three laboratories by members of the ICSB Subcommittee on the Taxonomy of Moraxella and Allied Bacteria. Eight of the strains were oxidase negative and could be classified as belonging to Acinetobacter. Of the 28 oxidase-positive strains, two were yellow-pigmented cocci, but differed markedly from neisseriae. A group of 11 rod-shaped strains, also pigmented to a greater or lesser extent, appeared related to Flavobacterium. Four unpigmented, mesophilic strains differed sufficiently to be unlikely members of Moraxella. Nine unpigmented psychrophilic strains, including two strains of Thornley's Phenon 3, showed similarities to moraxellae, although most of them oxidized aldose sugars like acinetobacters. Further taxonomic studies of the psychrophilic group will be of particular interest. The strains described by Bijsterveld (1970) and by Sutton et al. (1972) appeared to be nearly identical, but differed from moraxellae sufficiently to be unlikely members of Moraxella.
\end{abstract}

During the meetings of the ICSB Subcommittee on the Taxonomy of Moraxella and Allied Bacteria at the Xth International Congress for Microbiology in Mexico City in 1970, it was thought that certain organisms resembling moraxellae deserved study to see if they actually belonged to Moraxella or to other genera tentatively placed in the family Neisseriaceae. It was decided to gather a collection of such strains for joint studies by those members of the Subcommittee who desired to take part. It was agreed that the participating laboratories were free to select methods according to their own choice.

Three laboratories were interested in carrying out examination of the strain collection by conventional bacteriological methods, and this paper reports this part of the investigations. The results obtained by more highly specialized methods are expected to follow in later reports.

\section{MATERIALS AND METHODS}

The designations, sources, and origins of the strains are presented in Table 1. Each participating laboratory used tests and methods of its own choice. There are, consequently, considerable differences between the procedures used by the three laboratories. The designations of the laboratories, A (Oslo), B (Copenha- gen), and $\mathrm{C}$ (London) are used to indicate which methods were used by each laboratory. If the medium used in the test is not specified, it is to be understood that blood agar was used, with $5 \%$ human blood (A), $10 \%$ horse blood (B), and $5 \%$ horse blood (C).

Cell morphology. Cell morphology was determined by microscopy of Gram-stained films from 20- and 48-h-old cultures at room temperatures and at $35 \mathrm{C}$ (A), after $48 \mathrm{~h}$ at $30 \mathrm{C}$ (B), and after overnight incubation at $33 \mathrm{C}$ or $22 \mathrm{C}$ (C). Films stained by the method of Butt et al. (5) (A), or wet India ink preparations from mucoid colonies only (B), were examined for capsules.

Colony morphology. Colony morphology was observed daily for several days (A), after 48 and $72 \mathrm{~h}$ (B), or after overnight incubation (C) at the temperatures indicated above.

Pigmentation. Pigmentation was looked for on all solid media after 1 to about 10 days (A, B), or on nutrient agar and casein agar after 5 days (C) at the temperatures indicated in "cell morphology." When it became apparent that there were discrepancies between the laboratories, the strains in question were reexamined several times in laboratory $A$ on nutrient agar slants incubated at both temperatures (for revised results, see Table 3 ).

Motility. Motility was studied in semisolid motility agar at $35 \mathrm{C}$ and at room temperature (A), or in hanging drops from overnight broth cultures at $22 \mathrm{C}$ (C).

Twitching. Twitching was studied by plate micros- 
TABLE 1. Strains of Moraxella-like organisms included in this study ${ }^{a}$

\begin{tabular}{|c|c|c|c|c|c|}
\hline Strain & Origin & Source & Strain & Origin & Source \\
\hline WM17 & Lautrop & Lymph node biopsy & A 351 & $\begin{array}{l}\text { Thornley to } \\
\text { Lautrop }\end{array}$ & Poultry (Phenon 3) \\
\hline WM27 & Lautrop & Venule & A353 & Lautrop & Pus from abscess \\
\hline WM28 & Lautrop & Venule & A365 & Lautrop & Guinea pig, autopsy \\
\hline WM32 & Lautrop & Venule & A366 & Lautrop & Conjunctivitis \\
\hline WM34 & Lautrop & Venule & $\begin{array}{l}\text { "New Mor- } \\
\text { axella" }\end{array}$ & $\begin{array}{l}\text { Bijsterveld } \\
\text { to Henriksen }\end{array}$ & Conjunctivitis \\
\hline A163 & Lautrop & Plate contaminant & $\begin{array}{l}\text { "New Mor- } \\
\text { axella" }\end{array}$ & $\begin{array}{l}\text { Sutton to } \\
\text { Henriksen }\end{array}$ & Corneal abscess \\
\hline A259 & Lautrop & Urine & Pintér 16 & $\begin{array}{l}\text { Pintér to } \\
\text { Shewan }\end{array}$ & Clinical material \\
\hline A272 & Lautrop & Venule & Pintér 21 & $\begin{array}{l}\text { Pintér to } \\
\text { Shewan }\end{array}$ & Clinical material \\
\hline A273 & Lautrop & Venule & Henderson 55 & $\begin{array}{l}\text { Henderson } \\
\text { to Shewan }\end{array}$ & Soil \\
\hline A280 & Lautrop & Pleural fluid & Henderson 69 & $\begin{array}{l}\text { Henderson } \\
\text { to Shewan }\end{array}$ & Soil \\
\hline A285 & Lautrop & Venule & NCIB 9021 & Shewan & $\begin{array}{l}\text { Strain of Ferguson } \\
\text { and Roberts }\end{array}$ \\
\hline A317 & Lautrop & Urine & NCIB 9300 & Shewan & $\begin{array}{l}\text { A. metalcaligenes } \\
\text { from Brisou }\end{array}$ \\
\hline A 326 & Lautrop & Venule & NCMB 98 & Shewan & Lemon sole, gills \\
\hline A331 & Lautrop & Unknown & NCMB 131 & Shewan & Arctic cod, skin \\
\hline A332 & Lautrop & Skin & NCMB 168 & Shewan & Arctic cod, skin \\
\hline A333 & Lautrop & Unknown & NCMB 200 & Shewan & Skate, skin \\
\hline A338 & Lautrop & Spinal fluid & NCMB 307 & Shewan & Arctic cod, skin \\
\hline A348 & $\begin{array}{c}\text { Thornley to } \\
\text { Lautrop }\end{array}$ & Poultry (Phenon 3) & $\mathrm{MJT} / \mathrm{F} 4 / 5,7$ & $\begin{array}{l}\text { Thornley to } \\
\text { Shewan }\end{array}$ & Chicken \\
\hline
\end{tabular}

${ }^{a}$ Unless otherwise stated, all specimens of clinical material were of human origin.

copy of 6- to 8-, 24-, and 48-h-old cultures at $30 \mathrm{C}$ and $22 \mathrm{C}$, incubated in a humid atmosphere on a medium consisting of $0.05 \%$ tryptone, $0.05 \%$ yeast extract, and $1 \%$ agar (B) (all from Difco).

Temperature. Effects of temperature were studied using the following methods: incubation in closed jars with water at the bottom at $35,37,40$, and $42 \mathrm{C}$, and at room temperature (A); incubation at 37 and at $22 \mathrm{C}$ (B); incubation overnight at $22,30,33$, and $37 \mathrm{C}$, and at 5 and $45 \mathrm{C}$ for 5 days (C). In all other tests (see below), strains failing to grow at 35 to $37 \mathrm{C}$ were incubated at lower temperatures $(22 \mathrm{C}$ or room temperature).

Anaerobic growth. Anaerobic growth was examined after incubation in anaerobic jars in a hydrogen atmosphere for 3 days (A), or in $90 \%$ hydrogen and $10 \% \mathrm{CO}_{2}$ overnight (C).

Acid from carbohydrates. Tests were carried out with $1 \%$ solutions in Hugh and Leifson's $\mathrm{O} / \mathrm{F}$ medium (glucose both with and without vaseline seal) (A, B, C), in peptone water (glucose, lactose, maltose, sucrose and mannitol), and in Mueller-Hinton broth (glucose, maltose and sucrose). The method of Pickett and Pedersen (16) was also tried without giving additional information (A). Glucose was also tested in ammonium salt medium and peptone water (C), and observed for 14 days.

Starch hydrolysis. For the starch hydrolysis test, $1 \%$ starch in nutrient agar was used and was flooded with iodine after 5 days (C).

Catalase. For testing catalase, three different proce- dures were used. $\mathrm{H}_{2} \mathrm{O}_{2}(10 \%)$ was dropped on 20- to 24-h-old nutrient agar slope cultures (A). Growth from a 24-h-old nutrient agar culture was emulsified in a drop of $3 \% \mathrm{H}_{2} \mathrm{O}_{2}$ on a slide with a glass rod (B). A loopful of growth from nutrient agar was emulsified in $6 \% \mathrm{H}_{2} \mathrm{O}_{2}(\mathrm{C})$.

Oxidase. For the oxidase test, Kovacs' method (12) was used both with dimethyl- and tetramethyl-pphenylenediamine, $1 \%$ solutions (A). Kovacs' method with the tetramethyl compound was also used, with 20 (B) and 10 (C) $\mathrm{s}$ as the limit for a positive reaction.

Nitrate reduction. Nitrate broth $(0.2 \%)$ (11) was tested with sulfanilic acid and alpha-naphthylamine after 5 and 10 days, and with zinc powder in negative cases $(\mathrm{A}) ; 0.1 \%$ nitrate in peptone water was tested by the same method after 2 and 4 days (B); or $0.1 \%$ nitrate in peptone water was tested with sulfanilic acid and 1-naphthylamine-7-sulfonic acid after 5 days (C).

Nitrate reduction. Nitrite broth $(0.001 \%)$ was tested after 5 days with sulfanilic acid and 1-naphthylamine7-sulfonic acid (C).

Gelatin liquefaction. For the gelatin liquefaction test, culture in $15 \%$ gelatin in nutrient broth at room temperature was observed for 30 days (A). Stab cultures in $\mathrm{FeCl}_{3}$-gelatin medium (11) were incubated at $22 \mathrm{C}$ for 35 days (B). Nutrient gelatin stab cultures were observed for 28 days at $22 \mathrm{C} \mathrm{(C).}$

Serum liquefaction. For serum liquefaction, Loeffler serum slopes were observed for 30 (A) or 28 days (C).

Indole. To test for indole reaction, casein digest 
medium, incubated for 2, 5, and 10 days, was tested with Kovacs' reagent (A). Indole broth, incubated for 2 and 4 days, was tested with Ehrlich's reagent; the 96-h-old culture was shaken with 4 to 5 drops of xylene before adding the reagent (B). Nutrient broth, incubated for 5 and 10 days, was tested by Kovacs' and Ehrlich's methods (C).

Phenylalanine and tryptophan deamination. To test for phenylalanine and tryptophan deamination, a heavy suspension from blood agar cultures was made in $0.5 \mathrm{ml}$ of $0.1 \%$ L-phenylalanine (or saturated solution of DL-tryptophan:0.2\% DL-tryptophan did not quite dissolve) in water, preserved with $0.01 \%$ Merthiolate. The tubes were placed nearly horizontally at room temperature for $4 \mathrm{~h}$, after which 4 to 5 drops of $10 \% \mathrm{FeCl}_{3}$ were added. Results (green or red color) were recorded as "-," no color, "w," weak greenish or reddish color, and " + ," dark blackish-green or cherryred color (A). Cultures from 2-day-old agar plates were suspended to a density of about $2.5 \times 10^{9}$ bacteria per $\mathrm{ml}$ in $0.5 \%$ phenylalanine solution. To 2.5 $\mathrm{ml}$ of suspension, $0.5 \mathrm{ml}$ of borate-hydrochloric acid (pH 8) was added. Incubation was at $35 \mathrm{C}$ in a thin layer at the bottom of a flask; $0.3-\mathrm{ml}$ samples were taken after 4 and $22 \mathrm{~h}$, and 1 drop of $0.1 \mathrm{~N} \mathrm{HCl}$ and then two drops of $2 \% \mathrm{FeCl}_{3}$ were added. A strong green color after $1 \mathrm{~min}$ was considered a positive reaction. The green color did not become as deep blackish-green as with Proteus strains (B). Malonatephenylalanine broth, incubated for 2 days, was acidified with $0.1 \mathrm{~N} \mathrm{HCl}$ and a few drops of $\mathrm{FeCl}_{3}$ were added $(C)$.

Urease. In the urease test, Christensen's medium (6) was observed for 3 (A) or 5 days (C). A very heavy suspension was made in urea $(1 \%), \mathrm{KH}_{2} \mathrm{PO}_{4}(0.1 \%)$, $\mathrm{K}_{2} \mathrm{HPO}_{4}(0.1 \%), 5 \mathrm{ml}$ of phenol red per liter (1:500) (pH 7.1); readings were made after 2,4 , and $20 \mathrm{~h}$. Only change within $4 \mathrm{~h}$ was recorded as a positive reaction (B).

ONPG. The method of Le Minor and Hamida (13) was used for testing o-nitrophenyl- $\beta$-D-galacto-pyranoside (A). The method of Bülow $(2,3)(\mathrm{B})$, with ONPG broth was used for 5 days (C).

$\mathrm{H}_{2}$ S. In testing for $\mathrm{H}_{2} \mathrm{~S}$ production, triple sugar iron medium was observed up to 10 days (A). Lead acetate paper over cysteine nutrient broth was observed for 5 days (C).

Citrate utilization. Koser's citrate medium was observed for 10 (A) or 5 days (C) in the citrate utilization test. Hutner's medium (see reference 20 ) was used with $0.1 \%$ citrate as the only carbon and energy source. There were three passages in fluid medium before definitive reading (B).

Poly-beta-hydroxybutyrate inclusions. The medium of Cohen-Bazire et al. (7) was used, with $0.5 \%$ beta-hydroxybutyrate, and checked for inclusions by phase-contrast microscopy and after staining by the method of Burdon (4) as soon as growth was apparent (A). Basal medium of Owens and Keddie (15) was used with $0.5 \%$ beta-hydroxybutyrate; after 2 days the cells were stained with Sudan Black B and examined microscopically for inclusions (C). A phase-contrast microscope was used to observe cultures in fluid Hutner's medium, with $0.1 \%$ beta-hydroxybutyrate as the only carbon and energy source (B).

Growth in mineral media. To test for growth in mineral medium, Hutner's mineral base (20) was used with $0.1 \%$ acetate, butyrate, citrate, and ethanol as carbon source and $0.1 \%\left(\mathrm{NH}_{4}\right)_{2} \mathrm{SO}_{4}$ as nitrogen source. Three passages were made in fluid medium before the final reading (B).

Decarboxylases. Decarboxylases were tested with arginine, lysine, and ornithine by the method of Richard (17). A few strains failed to grow in the medium. The method of Shaw and Clarke (18) was also tested, but it failed in some instances because the suspensions would not sediment well on centrifugation and, therefore, were too alkaline (A). Arginine, lysine, and ornithine were tested in Mфller's medium using a heavy inoculum and incubating for 5 days (B and $\mathrm{C}$ ). Arginine was also tested by Thornley's method (22) for 5 days (C).

Penicillin sensitivity. The filter paper disk method of Ericsson (8) was first used to determine penicillin sensitivity. When the results showed marked differences from those of the other laboratories, probably because this method is unsuitable for such slowlygrowing and fastidious organisms as some of our strains, the tests were repeated in Todd-Hewitt broth tubes containing $1.0,0.1$, and 0.02 unit of penicillin $G$ per $\mathrm{ml}$ (A). Tests were done by Alice Reyn on gonococcus resistance plates in a series with known concentrations of penicillin (B). Saline suspensions of bacteria were inoculated on $5 \%$ horse blood agar plates containing 1 and 0.1 unit of penicillin $\mathrm{G}$ per $\mathrm{ml}$; they were incubated overnight (C).

Bile sensitivity. Overnight incubation was carried out on $5 \%$ horse blood agar ditch plates with $10 \%$ and $40 \%$ ox bile (C) to test bile sensitivity.

Phosphatase production. Phosphatase production was determined with $0.01 \%$ phenolphthalein phosphate in nutrient agar. After 2 days of incubation, it was exposed to ammonia (C).

Esculin hydrolysis. Esculin hydrolysis was tested on esculin/ferric chloride agar, with 10 days of incubation (C).

Casein digestion. Casein digestion was determined with $5 \%$ casein in nutrient agar plates, which were examined for clearing 5 days after inoculation (C).

Egg yolk opacity. Egg yolk opacity was tested with $1 \%$ egg yolk in nutrient agar after incubation for 5 days (C).

Tween hydrolysis. Tween hydrolysis was determined with $0.5 \%$ Tween in nutrient agar plus $0.01 \%$ $\mathrm{CaCl}_{2}$ (20); the inoculated medium was examined for precipitation after 5 days (C).

\section{RESULTS}

Eight of the strains were oxidase negative, both with the dimethyl- and tetramethyl-pphenylenediamine reagents. Other results obtained with these strains are shown in Table 2. The results are compatible with their classification as Acinetobacter strains, and therefore these strains were not studied further.

Results obtained with the remaining 28 strains are presented in Table 3. All of these strains gave positive oxidase reactions with both reagents. None of the strains attacked insulin or 
TABLE 2. Characters of oxidase-negative, gram-negative strains ${ }^{a}$

\begin{tabular}{|c|c|c|c|c|c|c|c|c|}
\hline \multirow[b]{2}{*}{ Characters } & \multicolumn{8}{|c|}{ Strains } \\
\hline & $\begin{array}{c}\text { Pintér } \\
16\end{array}$ & $\begin{array}{c}\text { Pintér } \\
21\end{array}$ & $\begin{array}{c}\text { Henderson } \\
55\end{array}$ & $\begin{array}{c}\text { Henderson } \\
69\end{array}$ & NCIB 9021 & NCIB 9300 & NCMB 168 & $\mathrm{MJT} / \mathrm{F} 4 / 5,7$ \\
\hline Size & sl & $\mathrm{p}$ & $s$ & $\mathrm{p}$ & $\mathrm{s} / \mathrm{p}$ & s & $\mathrm{s}$ & s \\
\hline Shape & $\mathrm{r}$ & o & $r$ & $0 / \mathrm{r}$ & $\mathrm{O} / \mathrm{r}$ & $\mathrm{r}$ & $\mathrm{c} / \mathrm{r}$ & $\mathrm{c}$ \\
\hline Arrangement & wd & d & $\mathrm{d}$ & $\mathrm{d}$ & wd & $\cdot$ & $\mathrm{d}$ & $\mathrm{d}$ \\
\hline Colony size & $s$ & $\mathrm{~s}$ & $s$ & $\mathrm{~s}$ & s & $\mathrm{m} / \mathrm{l}$ & $\mathrm{s}$ & $\mathrm{s}$ \\
\hline Phase $(\mathrm{M}, \mathrm{S})$ & $S$ & $S$ & $S$ & $\mathrm{~S}$ & $\mathrm{~S}$ & $\mathrm{~S}$ & $\mathrm{~S}$ & $\mathrm{~S}$ \\
\hline Growth, room temp & + & + & + & + & + & + & + & + \\
\hline Growth, $35 \mathrm{C}$ & w & + & + & - & + & + & - & - \\
\hline Glucose & - & - & + & - & - & + & w & - \\
\hline $\mathrm{O} / \mathrm{F}$ & & $\mathrm{O}$ & & & & $\mathrm{O}$ & $\mathrm{O}$ & \\
\hline Arabinose & - & $w$ & + & - & - & + & - & - \\
\hline Galactose & - & - & + & - & - & $w$ & $w$ & - \\
\hline Xylose & - & - & + & - & - & $w$ & $w$ & - \\
\hline Lactose & - & - & $w$ & - & - & $\mathrm{w}$ & - & - \\
\hline Urease & - & - & - & - & - & w & - & - \\
\hline Nitrate & - & - & - & - & - & - & - & + \\
\hline Citrate & - & - & + & - & + & + & $w$ & - \\
\hline Penicillin & M & M & $\mathrm{R}$ & M & $M$ & M & M & $S$ \\
\hline
\end{tabular}

${ }^{a}$ Symbols for penicillin: S, sensitive; M, moderate to low sensitivity; R, resistant. Other symbols as in Table 3 . The following reactions were uniformly negative: attack on sugars other than aldoses, indole, phenylalanine deaminase, $\mathrm{ONPG}, \mathrm{H}_{2} \mathrm{~S}$, gelatin liquefaction. The catalase reaction was uniformly positive.

inositol or decarboxylated amino acids. All strains grew at $30 \mathrm{C}$ and none of them grew at $45 \mathrm{C}$. They were all nonmotile.

A striking feature of Table 3 is the considerable number of discrepancies between the results obtained in different laboratories. Some of these discrepancies, e.g., evaluation of size and shape of the bacterial cells and appearance of the colonies, can be explained by the purely subjective nature of the observations.

Other discrepancies are quite obviously due to differences in technique and/or media, e.g., the tests for $\mathrm{H}_{2} \mathrm{~S}$ production and phenylalanine deamination. The phenylalanine test showed the largest number of differences, mainly because the method used in laboratory $A$ is more sensitive than those used in laboratories B and $\mathrm{C}$. Even in laboratory $\mathrm{A}$, however, most of the positive reactions were weak, far weaker than reactions given by Proteus strains, and probably of little significance in taxonomy. When the strains which gave weak positive reactions with phenylalanine were tested for deamination of tryptophan, they gave negative reactions. Only the strains A348, A351, A353, NCMB 307, NCMB 131, and NCMB 200 deaminated both amino acids, and with much stronger reactions than any of the other strains. When laboratories $\mathrm{B}$ and $\mathrm{C}$ reported negative results with these strains, it became necessary to investigate this matter further. In repeated tests with these two reactions under varied conditions, suspensions of these strains from blood agar gave stronger reactions than suspensions from nutrient agar (Mueller-Hinton medium), which sometimes gave negative reactions. Suspensions from 2- to 3-day-old cultures gave stronger reactions than suspensions from 24-h-old cultures, which sometimes gave very weak or negative reactions. Finally, very heavy suspensions of the strains were needed to obtain strong positive results by the method used in laboratory $\mathbf{A}$. When attention was paid to these experimental conditions, the more strongly positive strains mentioned above gave stronger deaminase reactions than the other strains, although not quite as strong as a Proteus control strain.

The discrepancies in the tests for anaerobic growth (a difference between no growth in one laboratory and minimal growth in another), gelatin liquefaction, and nitrate reduction can probably also be ascribed chiefly to differences in techniques and media.

The variation in assessment of pigment production may be due partly to different media and incubation times. When the discrepancies became known, tests for pigment production were repeated in laboratory $A$, using nutrient agar slopes and blood agar plates with incubation extended for 1 week or more. A few of the discrepancies were eliminated by this procedure. The repeated tests appeared to confirm pigment production by all strains which have received the symbols " + " or " $+1-$ ", in Table 3, except strain A365, in which case 


\begin{tabular}{|c|c|c|c|}
\hline \multirow{2}{*}{\multicolumn{2}{|c|}{ 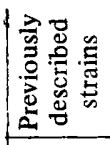 }} & uolfns & $\overline{\operatorname{su}} \boldsymbol{x} \cos \left|\frac{1}{f}\right| 1 \mid+$ \\
\hline & & рјәмдәтs!!g & $11 \frac{1}{3}+\frac{1}{0}+++\frac{1}{3} \frac{1}{3} 31 \frac{1}{+}+1+311 \frac{1}{3}$ \\
\hline & \multirow{9}{*}{ 产 } & $99 \varepsilon V$ & $1 \mid 1+0++1++++\frac{1}{3} 1++111111$ \\
\hline & & $00 Z$ gWวN & 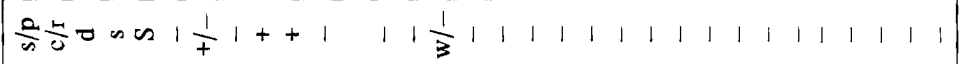 \\
\hline & & IEI gWDN & 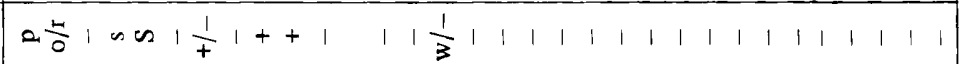 \\
\hline & & LOE ЯWON & $11 \frac{1}{3}+0++1++++\frac{1}{3} 1++111111$ \\
\hline & & 86 gWวN & $11 \frac{1}{3}+0++1++++11++111111$ \\
\hline & & $\varepsilon \varsigma \varepsilon \forall$ & $113+0++1++++\frac{1}{+} 1++11111$ \\
\hline & & ISEV & $113+0++1++++\frac{1}{3} 1++1 \quad 1 \quad 1 \quad 1$ \\
\hline & & $8 t \varepsilon \forall$ & $113+0++1+++\frac{1}{+} 11++11111$ \\
\hline & & $\varepsilon \mathcal{E} \mathcal{E}$ & 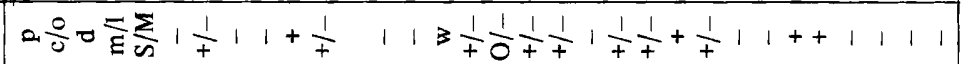 \\
\hline & \multirow{4}{*}{ 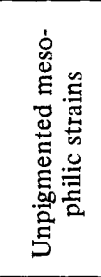 } & S9EV & 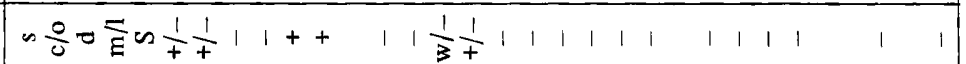 \\
\hline & & $\tau \varepsilon \varepsilon \forall$ & 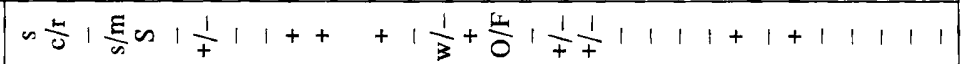 \\
\hline & & $082 \mathrm{~V}$ & 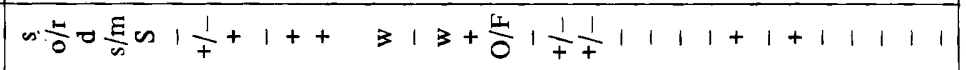 \\
\hline & & ZEWM & $313+1+1 \frac{1}{f} \frac{1}{f}|1| 1|c|+1+1 \mid \begin{array}{llll}1 & 1 & 1 & 1\end{array}$ \\
\hline & $\varepsilon\llcorner Z \forall$ & $\infty \frac{t}{0} 1 \frac{\sum}{n}+111+++13+i \leqslant \frac{1}{f} 11111+\frac{1}{3} 1+1|1| 1 \mid$ \\
\hline & & $Z L Z \forall$ & $+13+43 \frac{1}{+} \frac{1}{3} 1111+\frac{1}{+} 1+1111$ \\
\hline & & \$8Z & $313+\frac{1}{1} 1 \frac{1}{f} 11111+11+1111$ \\
\hline & & $6 S Z V$ & 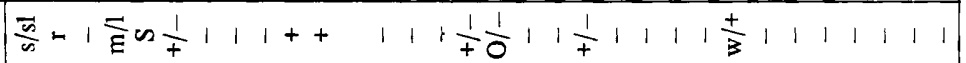 \\
\hline & & E9IV & $313+0 \frac{1}{f}+1|1| 1|1+1| 1311111$ \\
\hline & & $8 \varepsilon \varepsilon \forall$ & $13 \frac{1}{3}+0+\frac{1}{f} \frac{1}{+}++++31++1 \quad 1 \quad 1 \quad 1$ \\
\hline & & I $\varepsilon \varepsilon \forall$ & $+1 \frac{1}{3}+0+++++3+++++++++$ \\
\hline & & $9 \tau \varepsilon \forall$ & $313+0++++++++++++31$ \\
\hline & & $\neg \varepsilon W M$ & $+1 \frac{1}{3}+0+++1+++++++++1$ \\
\hline & & $q^{(g ' v) ~ 8 Z W M}$ & $313+03++111++\frac{1}{t}++++31$ \\
\hline & & $q(g ` V) \angle Z W M$ & $311+0++\frac{1}{t} 111++\frac{1}{+}++3+11$ \\
\hline & & $q\left(D^{\prime} \forall\right)<I \varepsilon \forall$ & $333+0+++++\frac{t}{3} 1$ \\
\hline & & $q\left(\partial^{\prime} \forall\right)<$ INM & $+33+0+++++\frac{t}{3} 11$ \\
\hline \multicolumn{3}{|r|}{ 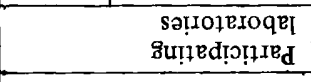 } & 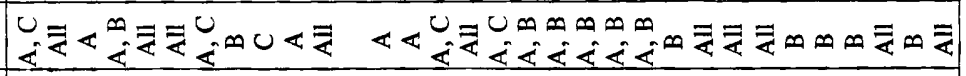 \\
\hline & \multirow{2}{*}{\multicolumn{2}{|c|}{ 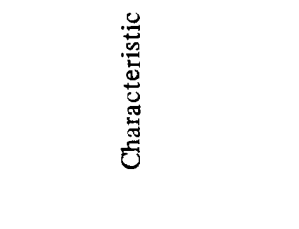 }} & 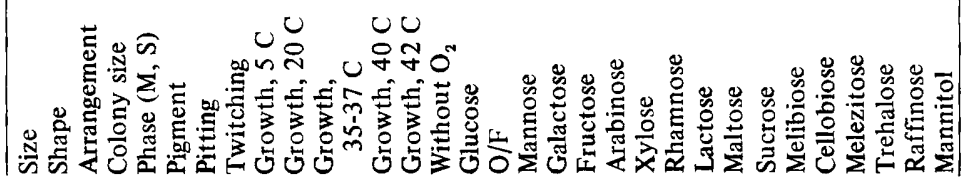 \\
\hline & & & \\
\hline
\end{tabular}




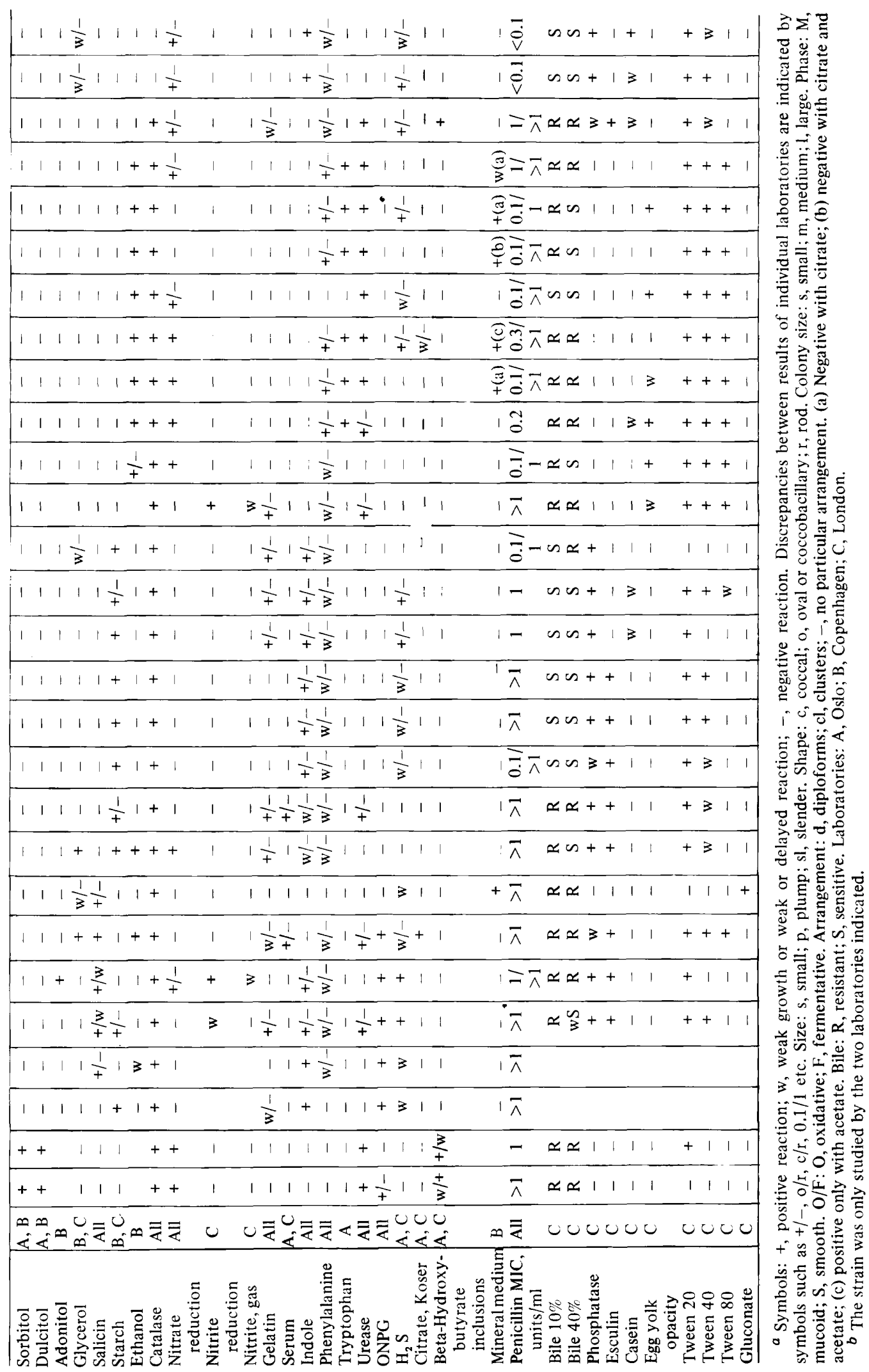


pigment production was not detected. The strains WM17 and A317 showed marked lemon-yellow pigmentation after growth on blood agar in a humid atmosphere for 5 to 6 days. The many discrepanices between the results of fermentation tests may be due partly to the nutritional inadequacy of Hugh and Leifson's medium, partly to the use of additional media in some laboratories, and partly perhaps to the fact that some strains produced extremely small quantities of acid. Some discrepancies must, however, be attributed to technical errors or mistakes.

Strain A333 showed marked test differences between laboratories, especially in the production of acid from aldose sugars. Repeat tests showed that growth of this strain was much better at room temperature than at 35 or $37 \mathrm{C}$ and that the strain produced acid from aldose sugars only at temperatures below $35 \mathrm{C}$.

The differences in the indole reactions observed are disturbing. These reactions were repeated several times in laboratory $\mathrm{A}$, and positive reactions were obtained each time for those strains which showed differences between the laboratories in Table 3 . The reactions were weak, however, and the color appeared more yellow than usual, although distinctly different from the negative control strains. The identity of the substance giving these color reactions has not been determined.

The first results for penicillin sensitivity (not shown in Table 3 ) were very inconsistent, and the results from laboratory A showed much higher sensitivities than those of the other laboratories. Repeated tests in laboratory A with fluid media containing penicillin instead of the filter paper disk method reduced or eliminated some of the discrepancies. Thus, the diffusion method did not appear to be suitable for such fastidious and slowly growing organisms as some of the strains in the collection.

\section{DISCUSSION}

The results indicate that many bacteriological tests are highly dependent upon the techniques used. This is particularly true of tests for production of $\mathrm{H}_{2} \mathrm{~S}$ and deamination of phenylalanine. In the original description of the phenylalanine test (9), certain modifications of the procedure were shown to result in weak positive reactions with some organisms which otherwise gave negative reactions. This is unimportant when the test is used for members of the family Enterobacteriaceae, where the test is most useful for taxonomic purposes and where moderate variations of the technique do not appear to alter the results. But with organisms such as those studied in this work, the weak to moderate reactions are quite confusing. The results suggest that deamination of tryptophan, which does not appear to give such weak reactions, may be preferable or that both tests should be used in taxonomic work outside the family Enterobacteriaceae.

The strains listed in Table 3 can be subdivided into several groups which are more or less uniform. The strains WM17 and A317 are very similar. They are both plump cocci which do not produce rod-shaped cells even when growing in the presence of subinhibitory concentration of penicillin (10). Both produce mucoid colonies that, after growth on blood agar for several days, develop a lemon-yellow pigment. They oxidize a wide range of carbohydrates, including the alcohols sorbitol and dulcitol, split urea, and store poly-beta-hydroxybutyrate granules. These strains resemble neisseriae to some extent-in cell shape, pigment production, oxidase reaction, and oxidative attack on sugars-but they differ from Neisseria species in attack on sugar alcohols, urease production, and in storing poly-beta-hydroxybutyrate. It seems probable that they are not closely related to neisseriae.

The strains WM27, WM28, WM34, A326, A331, A338, A163, A259, A285, A272, and A273 appear to form a group with some common features. They are in general small, slender organisms which were found to produce pigment in at least two of the laboratories. With two exceptions (A331 and A338), they give color reactions with Kovacs' indole reagent (some discrepancies). But there are also marked differences between the strains, except for strains WM27 and WM28, which appear to be closely interrelated, and strains A272 and A273, which are nearly identical and appear to form another sub-group together with strain A285. The differences from moraxellae in pigmentation, cell size, biochemical reactions, and response to penicillin make it unlikely that these strains are closely related to moraxellae. More probably they could be fitted into the ill-defined genus Flavobacterium.

The unpigmented strains WM32, A280, A332, and A365 also have small cells which do not resemble moraxellae. Three of them (WM32, A280, and A332) are apparently closely interrelated, whereas the fourth (A365) may be different. It is unlikely that any of these strains will eventually prove to belong to the genus Moraxella. Possibly, they may also be found to fit into the genus Flavobacterium in spite of their lack of yellow pigment. 
The unpigmented strains A333, A348, A351, A353, A366, NCMB 98, NCMB 307, NCMB 131 , and NCMB 200 show very slight or no growth at 35 to $37 \mathrm{C}$. All grow well at room temperature and all except A333 and A366 grow at $5 \mathrm{C}$. With some exceptions, as indicated, the strains have the following main characteristics: plump cells in diplo-arrangement (A366 appeared to have somewhat smaller cells, laboratory A), urease production (except A333), fairly strong tryptophan deamination (except A333, NCMB 98, and A366), and reasonable sensitivity to penicillin (NCMB 200 and A.366 slightly less sensitive). Strain A366 is exceptional in having markedly mucoid colonies and in storing poly-beta-hydroxybutyrate, and it appears different. Like acinetobacters, seven strains oxidized all the aldose sugars tested but did not attack any other sugars. These strains corresponded to Thornley's (23) Phenon 3 and appear to represent a rather homogeneous and well-defined group. The two remaining strains (NCMB 131 and NCMB 200) do not attack sugars and are the two strains in the collection showing the greatest resemblance to moraxellae. These psychrophilic strains may be related to Acinetobacter, as suggested by Thornley (23), or to Moraxella, or may represent an intermediate group between the two genera. Further taxonomic studies of these organisms are needed.

The strains of Bijsterveld (1) and of Sutton et al. (21) were both isolated from eye infections, and the results indicate that they are nearly identical. They differ from moraxellae in morphology, as they produce rather long slender rods, and by their attack on several sugars and production of indole, although they are sensitive to penicillin. These strains should not be classified as moraxella without genetic evidence, and may represent a new species, which might, perhaps, be classified in one of the genera of Brucellaceae, or possibly in a genus of their own.

The oxidase-negative strains were classified as acinetobacters and are not, therefore, further discussed in this paper.

\section{ACKNOWLEDGMENT}

We thank Alice Reyn, Statens Seruminstitut, Copenhagen, for her help with the penicillin sensitivity tests.

\section{REPRINT REQUESTS}

Address reprint requests to: Dr. S. D. Henriksen, Bacteriological Institute, Rikshospitalet, Oslo 1, Norway.

\section{LITERATURE CITED}

1. Bijsterveld, O. P. van. 1970. New Moraxella strain isolated from angular conjunctivitis. Appl. Microbiol. 20:405-408.

2. Bülow, P. 1964. The ONPG test in diagnostic bacteriology. 1. Methodological investigations. Acta Pathol. Microbiol. Scand. 60:376-386.

3. Builow, P. 1964, The ONPG test in diagnostic bacteriology. 2. Comparison of the ONPG test and the conventional lactose fermentation test. Acta Pathol. Microbiol. Scand. 60:387-402.

4. Burdon, K. L. 1946. Fatty material in bacteria and fungi revealed by staining dried, fixed slide preparations. J. Bacteriol. 52:665-678.

5. Butt, E. M., B. W. Bonynge, and R. L. Joyce. 1936. The demonstration of capsules about hemoly tic streptococci with India ink or azo blue. J. Infect. Dis. 58:5-9.

6. Christensen, W. B. 1946. Urea decomposition as a means of differentiating Proteus and paracolon cultures from each other and from Salmonella and Shigella types. J. Bacteriol. 52:461-466.

7. Cohen-Bazire, C., W. R. Sistrom, and R. Y. Stanier. 1957. Kinetic studies of pigment synthesis by non-sulphur purple bacteria. J. Cell. Comp. Physiol. 49:25-68.

8. Ericsson, H. 1960. Rational use of antibiotics in hospitals. Studies in laboratory methods and discussion of the biological basis for their clinical application. Scand. J. Clin. Lab. Invest. 12: Suppl. 50.

9. Henriksen, S. D., and K. Closs. 1938. The production of phenylpyruvic acid by bacteria. Acta Pathol. Microbiol. Scand. 15:101-113.

10. Kaftka, A. 1964. Zur Taxonomie und Pathogenität der Moraxellen. Arch. Hyg. Bakteriol. 148:379-387.

11. Kauffmann, F. 1966. The bacteriology of Enterobacteriaceae, p. 366, 370. Munksgaard, Copenhagen.

12. Kovacs, N. 1956. Identification of Pseudomonas pyocyanea by the oxidase reaction. Nature (London) 178:703.

13. Le Minor, L., and F. Ben Hamida. 1962. Avantages de la recherche de la $\beta$-galactosidase sur celle de la fermentation du lactose en milieu complexe dans le diagnostic bactériologique, en particulier dés Enterobacteriaceae. Ann. Inst. Pasteur 102:267-277.

14. Lowe, G. H. 1962. The rapid detection of lactose fermentation in paracolon organisms by the demonstration of $\beta$-D-galactosidase. J. Med. Lab. Technol. 19:21-25.

15. Owens, J. D., and R. M. Keddie. 1968. A note on the vitamin requirements of some coryneform bacteria from soil and herbage. J. Appl. Bacteriol. 31: 344-348.

16. Pickett, M. J., and M. M. Pedersen. 1970. Characterization of saccharolytic, nonfermentative bacteria associated with man. Can. J. Microbiol. 16:351-462.

17. Richard, C. 1968. Techniques rapides de recherche des lysine-décarboxylase, ornithinedécarboxylase et arginine-dihydrolase dans les 
genres Pseudomonas, Alcaligenes et Moraxella. Ann. Inst. Pasteur 114:425-430.

18. Shaw, C., and P. H. Clarke. 1955. Biochemical classification of Proteus and providence cultures. J. Gen. Microbiol. 13: 155-161.

19. Sierra, G. 1957. A simple method for the detection of lipolytic activity of micro-organisms and some observations on the influence of the contact between cells and fatty substrates. Antonie van Leeuwenhoek J. Microbiol. Serol. 23: 15-22.

20. Stanier, R. Y., N. J. Palleroni, and M. Doudoroff. 1966. The aerobic pseudomonads: a taxonomic study. J. Gen. Microbiol. 43: 159-271.

21. Sutton, R. G. A., M. F. O'Keeffe, M. A. Bundock, J. Jeboult, and M. P. Tester. 1972. Isolation of a new Moraxella from a corneal abscess. J. Med. Bacteriol. 5:148-150.

22. Thornley, M. J. 1960. The differentiation of Pseudomonas from other Gram-negative bacteria on the basis of arginine metabolism. J. Appl. Bacteriol. 23:37-52.

23. Thornley, M. J. 1967. A taxonomic study of Acinetobacter and related genera. J. Gen. Microbiol. 49:211-257. 